\title{
Increased expression of the homologue of enhancer-of-split 1 protects neurons from beta amyloid neurotoxicity and hints at an alternative role for transforming growth factor beta 1 as a neuroprotector
}

\author{
Pedro J Chacón* and Alfredo Rodríguez-Tébar
}

\begin{abstract}
Introduction: Alzheimer's disease (AD) is a neurodegenerative disorder characterized by the deposition of $\beta$-amyloid (A $\beta)$ in the brain, which produces progressive neuronal loss and dementia. We recently demonstrated that the noxious effects of $A \beta$ on cultured hippocampal neurons are in part provoked by the antagonism of nerve growth factor (NGF) signalling, which impairs the activation of nuclear factor $\kappa \mathrm{B}$ (NF- $\kappa \mathrm{B}$ ) by impeding the tyrosine phosphorylation of $\mathrm{I}-\kappa \mathrm{B} \alpha$. As a result, the expression of the homologue of Enhancer-of split 1 (Hes 1) gene is downregulated and ultimately, gamma-aminobutyric acid (GABA)-ergic connectivity is lost.

Methods: Hes 1 activity was promoted in cultured hippocampal neurons by overexpressing a Hes1-encoding plasmid or by upregulating this gene by activating NF- $\kappa$ B through different approaches (overexpressing either the $1-\kappa B$ kinase $\beta$, or p65/RelA/NF- $\kappa$ B). Alternatively neurons were exposed to TGF $\beta$ 1. Dendrite patterning, GABAergic connectivity and cell survival were analyzed by immunofluorescence microscopy. Hes 1 expression was determined by real-time PCR. NF- $\kappa$ B activation was measured using the dual-luciferase reporter assay.
\end{abstract}

Results: The expression of Hes 1 abolished the effects of $A \beta$ on dendritic patterning and GABAergic input, and it prevented the death of the cultured neurons. TGF $\beta 1$, a known neuroprotector, could counteract the deleterious effects of $A \beta$ by inducing NF- $\kappa B$ activation following the serine phosphorylation of $1-\kappa B \alpha$. Indeed, the number of GABAergic terminals generated by inducing Hes1 expression was doubled.

Conclusion: Our data define some of the mechanisms involved in A $\beta$-mediated cell death and they point to potential means to counteract this noxious activity.

\section{Introduction}

The amyloid hypothesis considers amyloid beta $(A \beta)$ as the principal agent underlying the various manifestations of Alzheimer's disease (AD). Accordingly, most therapeutic approaches for $\mathrm{AD}$ treatment target the $\mathrm{A} \beta$ peptide, which induces the formation of amyloid deposits in the brain [1]. These strategies attempt to limit $A \beta$ production and fibril formation, or to increase $A \beta$ clearance from brain deposits. This latter approach has been the focus of

\footnotetext{
* Correspondence: pedro.chacon@cabimer.es

Centro Andaluz de Biología Molecular y Medicina Regenerativa (CABIMER), Americo Vespucio s/n, Isla de la Cartuja, 41092 Seville, Spain
}

much investigation, with active and passive methods to immunize against $A \beta$ effectively reducing brain $A \beta$ content. However, this reduction in amyloid content has not been conclusively associated with improvements in cognitive performance or a slowing in the progression of $\mathrm{AD}$ $[2,3]$.

An alternative approach to AD therapy involves interfering with the signals transduced by $A \beta$ to offset neuronal deterioration and death. While neuronal $A \beta$ signaling pathways have been studied extensively, many of the underlying mechanisms remain elusive. Several studies have related $\mathrm{A} \beta$ neurotoxicity with NGF neurotrophy

\section{C) Biomed Central}


and indeed, some current therapeutic approaches for $\mathrm{AD}$ involve the use of NGF or other compounds that mimic its effects [4-9]. The cellular and molecular bases underlying the antagonism of NGF by $A \beta$ have been described recently, at least in part. Accordingly, $\mathrm{A} \beta$ competes with nerve growth factor (NGF) binding to p $75^{\mathrm{NTR}}[10,11]$, thereby preventing the activation of NF- $\kappa \mathrm{B}$ by impairing the tyrosine phosphorylation and the subsequent degradation of I- $\kappa \mathrm{B} \alpha$ [12]. The inhibition of nuclear factor kappa-B (NF- $\kappa \mathrm{B})$ mediated by $\mathrm{A} \beta$ results in the downregulation of the enhancer of split homolog 1 (Hes1) gene, which is known to influence dendrite patterning and gamma-aminobutyric acid (GABA)-ergic inputs [13,14].

We recently reported that $A \beta$ impairs the initial steps of NGF signalling at the level of RhoA GTPase and protein tyrosine phosphatase 1B (PTP1B) [15]. Furthermore, we demonstrated that potentiation of NGF signalling (for example, by inhibiting RhoA GTPase and activating PTP1B) confers neuronal resistance to $A \beta$ neurotoxicity. In the present study, we explored alternative means of activating NF- $\kappa \mathrm{B}$ and promoting Hes 1 expression. We found that overexpression of I- $\kappa \beta$ kinase (IKK $\beta)$ a kinase that phosphorylates I- $\kappa \mathrm{B} \alpha$ (an NF- $\kappa \mathrm{B}$ inhibitor), p65/ RelA or Hes 1 abolished the effects of $A \beta$ on dendritic patterning, GABAergic input and the survival of cultured hippocampal neurons. Furthermore, administration of transforming growth factor $\beta 1$ (TGF $\beta 1$ ) produced similar effects, augmenting Hes 1 expression and GABAergic input, and conferring resistance to $A \beta$ toxicity. These results further our understanding of $A \beta$ toxicity in $A D$ and they open new perspectives for $\mathrm{AD}$ treatment using anti-amyloid approaches.

\section{Materials and methods Antibodies}

The following primary antibodies were used for immunocytochemistry: rabbit anti-enhanced green fluorescent protein (EGFP, 1:500: Invitrogen, Carlsbad, CA, USA), chicken anti-EGFP (1:500: Chemicon, Hampshire, UK), mouse anti-Myc (1:400: Roche Applied Science, Mannheim, Germany), mouse anti-FLAG (1:500: SigmaAldrich, Madrid, Spain) and rabbit anti-vesicular inhibitory amino acid transporter (VIAAT, 1:400: Chemicon). The following secondary antibodies were used: goat anti-rabbit $C y^{2}$ (1:1000), goat anti-mouse $\mathrm{Cy}^{3}$ (1:1000), goat anti-rabbit $\mathrm{Cy}^{3}$ (1:1000) and goat-anti mouse $\mathrm{Cy}^{5}$ (1:500: all from Jackson Immuno Research, West Grove, USA), and goat anti-chicken Alexa-fluor 488 (1:1000: Invitrogen).

\section{Amyloid $\beta$ preparation and characterization}

Amyloid $\beta$ (1-42) was purchased from NeoMPS (Strasbourg, France) and to obtain oligomeric forms, the peptide was dissolved in 1,1,1,3,3,3-hexafluoro-2-propanol and the solution was allowed to evaporate for $2 \mathrm{~h}$ at room temperature. The peptide film was dissolved in dimethyl sulfoxide (DMSO), sonicated in a water bath for $10 \mathrm{~min}$ utes and diluted to $100 \mu \mathrm{M}$ in PBS. This solution was then briefly vortexed and incubated overnight at $4{ }^{\circ} \mathrm{C}$. Aliquots were stored at $-20^{\circ} \mathrm{C}$. Our $\mathrm{A} \beta$ preparations were resolved by $12 \%$ Bis-Tris gel electrophoresis and electrotransferred to polyvinylidene difluoride (PVDF) membranes, which were probed with a mouse monoclonal anti- $\beta$ Amyloid antibody (clone BAM-10, diluted 1:2,000: Sigma Aldrich). After further incubation with an horseradish peroxidise (HRP)-conjugated anti-mouse antibody (1:10,000: Jackson Immuno Research, West Grove, USA), immunoreactive $\mathrm{Ab}$ species were visualised by chemiluminiscence. This analysis revealed that most $\mathrm{A} \beta$ forms were monomeric and dimeric with a less prominent trimeric and tetrameric component (Figure S1A in Additional file 1). To kill neurons in culture, a concentration of $5 \mu \mathrm{M}$ was established empirically (Figure S1B in Additional file 1).

\section{Other chemicals}

Recombinant TGF $\beta 1$ was purchased from Preprotech EC LTD (London, UK). The cell-permeable NF- $\kappa \mathrm{B}$ inhibitor peptide SN-50 and its inactive control, SN-50M, were obtained from Calbiochem (Darmstadt, Germany).

\section{Expression vectors for neuronal transfection}

EGFP-expressing vector (pEGFP-N1) was obtained from Biosciences/Clontech (Palo Alto, CA, USA). Vectors expressing the wild type (wt) forms of IKK $\alpha$ (pCDNAHA-IKK $\alpha$ ) and IKK $\beta$ (pRK5cFLAG-IKK $\beta$ ) were kindly provided by Lisardo Boscá [16]. Vectors encoding mutant forms of I- $\kappa \mathrm{B} \alpha$ (3XFLAG-pCMV-I- $\kappa \mathrm{B} \alpha \mathrm{S} 32 / 36 \mathrm{~A}$ and 3XFLAG-pCMV-I- $\kappa \mathrm{B} \alpha \mathrm{Y} 42 \mathrm{~F}$ ) were described previously [17]. A FLAG-tagged vector encoding p65/RelA (pCMVTag1-p65) was kindly provided by Mayte Coiras [18]. Vectors encoding Hes1 (pCLIG-Hes1) and Hes6 (pIRES-Hes6) were kindly provided by Ryoichiro Kageyama [19] and Phil Jones [20], respectively. Myc-tagged forms of Hes1 and Hes6 were obtained by inserting the corresponding cDNA encoding sequence from previous vectors into the NcoI/ EcoRI and NcoI/StuI sites of the pCS2+MT vector.

\section{Cell culture}

Primary hippocampal neuronal cultures were prepared as described previously [21], with some modifications. Briefly, hippocampi were dissected from embryonic day 17 (E17) CD1 mouse foetuses and dissociated into single cells following trypsin digestion (Worthington, Lakewood, USA) and DNase I treatment (Roche Applied Science). Neurons were plated on glass coverslips or in plastic dishes coated with poly-L-lysine (Sigma-Aldrich, Madrid, Spain), and then cultured in Neurobasal A supplemented with $2 \mathrm{mM}$ GlutaMAX I, 100 units/mL penicillin and $100 \mu \mathrm{g} / \mathrm{mL}$ streptomycin (Gibco BRL, Crewe, UK). After 7 days 
in vitro (DIV) the neurons were exposed to either TGF $\beta 1$ or $\mathrm{A} \beta$.

\section{Neuronal transfection}

For fluorescence immunocytochemistry, cultured neurons (7 days in vitro, DIV) were transfected with different vectors using the Effectene Transfection Reagent (Qiagen $\mathrm{GmbH}$, Hilden, Germany) according to the manufacturer's instructions, with some modifications. Briefly, $0.6 \mu \mathrm{g}$ of DNA was added to $120 \mu \mathrm{l}$ of EC buffer and $3.5 \mu \mathrm{L}$ of enhancer, and then left for 5 minutes at room temperature before $10 \mu \mathrm{L}$ of Effectene was added. After 15 minutes incubation at room temperature, the final solution was added to a $35 \mathrm{~mm}$ cell culture dish containing hippocampal neurons, for $3 \mathrm{~h}$ before the medium was changed. Less than $0.5 \%$ of the neurons were transfected in each dish, permitting the morphology of the neurons to be analyzed without the interference of neighboring labeled neurons. To determine Hes 1 mRNA, 300,000 neurons were transfected with different vectors using Lipofectamine LTX (Invitrogen), following the protocol recommended by the manufacturer. The rate of transfection was $20-25 \%$ of the total number of cells.

\section{Immunocytochemistry, image acquisition and} morphometric analysis of labeled hippocampal neurons

Neurons were fixed for 30 minutes in $4 \%$ paraformaldehyde (PFA) in PBS $18 \mathrm{~h}$ after transfection, permeabilized for 15 minutes at room temperature with $0.5 \%$ Triton $\mathrm{X}-100$ in PBS and blocked with $10 \%$ goat serum in PBS containing $0.1 \%$ Triton $\mathrm{X}-100$. The neurons were then incubated with the primary and secondary antibodies. To verify that the labeling was caused specifically by the primary antibodies, it was either omitted or replaced by similarly diluted normal serum from the same species.

Our methods for the evaluation of dendritic morphology and presynaptic terminal identification in dissociated cell cultures have been described previously [14]. Briefly, labeled neurons were visualized by standard epifluorescence under a Plan-Neofluar $63 \times$ oil objective with a numerical aperture of 1.3 (Zeiss, Oberkochen, Germany). Terminal counts and analysis of dendrite morphology were performed manually. A circular region of interest (ROI) with a diameter of $50 \mu \mathrm{m}$ was projected onto the EGFP-labeled neuron, its centre roughly coinciding with the centre of the soma. The dendrite length was expressed as the number of dendritic trees that exceeded the limit of the ROI (number of dendrites $>50 \mu \mathrm{m}$ ). In co-transfection experiments, only double-labeled cells were analysed, representing $>90 \%$ of the single-labeled cells. Synaptic terminals in contact with an EGFP-labeled neuron were identified by single immunofluorescence, when an antibody against VIAAT was used.

\section{Cell survival}

After treatment, neurons were fixed for 30 minutes in $4 \%$ paraformaldehyde (PFA) in PBS and the nuclei were immunostained with the fluorescent dye 4',6-diamidino2-phenylindole (DAPI: Sigma-Aldrich). Non-viable neurons were recognized by nuclear condensation and/or fragmented chromatin. In two independent experiments, the number of viable neurons was counted in triplicate in approximately 50 fields. In co-transfection experiments, only the nuclei of double-labeled cells were analysed.

\section{Quantitative real time polymerase chain reaction (PCR)}

After treatments, total RNA was extracted from cultures at 7 DIV using the Illustra RNAspin Mini kit (GE-Healthcare, Piscataway, NJ, USA) and first strand cDNA was prepared from the RNA using the First Strand Synthesis kit according to the manufacturer's instructions (Fermentas GmbH, St Leon-Rot, Germany). Quantitative PCR was performed using the ABI Prism 7000 Sequence Detector (Applied Biosystems, Weiterstadt, Germany). TaqMan probes and primers for Hes 1 and the housekeeping gene $G A D P H$ (as a control) were selected as the Assay-onDemand gene expression products (Applied Biosystems). All TaqMan probes were labeled with 6-carboxy fluorescein (FAM) and real time PCR was performed using the TaqMan Universal PCR Master Mix according to the manufacturer's instructions. Hes1 expression was normalized to GAPDH expression.

\section{Analysis of reporter gene activity}

For reporter gene studies, 12-well plates (Becton Dickinson) containing 200,000 hippocampal neurons were transfected using the Lipofectamine LTX (Invitrogen) transfection reagent according to the manufacturer's instructions. Transfection efficiency ranged from 20 to $25 \%$ in control experiments, as revealed by co-transfection with pEGFPN1 (Biosciences/Clontech). Cells were co-transfected with $0.5 \mu \mathrm{g} /$ well of a plasmid containing five tandem repeats of the $\kappa \mathrm{B}$ enhancer element upstream of the coding sequence of firefly-luciferase (pNF- $\kappa \mathrm{B}$-luc; Clontech), along with $0.1 \mu \mathrm{g}$ of a plasmid encoding Renilla-luciferase (phRL-TKluc: Promega, Madison, WI) as a transfection control for normalization in dual-luciferase assays. Dual-Luficerase reporter assays were performed according to the manufacturer's recommendations (Promega).

\section{Statistical analysis}

The data are presented as the mean \pm standard error of the mean (SEM). Unpaired Student's $t$-tests were used to determine the significance, denoted as ${ }^{*} P<0.05$, ${ }^{* *} P<$ 0.01 , and ${ }^{* * *} P<0.001$. All experiments were repeated at least twice. 


\section{Results}

Hes1 in neuronal morphology, connectivity and survival

Earlier studies revealed that Hes 1 mediates the effects of NGF on neuronal morphology and connectivity. NGF increases both dendrite length and GABAergic connectivity in cultured hippocampal neurons, effects that are abrogated by overexpression of Hes6 [13,14], a natural inhibitor of Hes1 [19]. We transfected a Hes1-expressing vector into cultured hippocampal neurons and analyzed the effects on dendrite morphology and synaptic connectivity. Overexpression of Hes 1 increased the length of primary dendrites while decreasing their number (Figure 1A, $B$ ), and it enhanced GABAergic connectivity, as evident by immunostaining for VIAAT-positive clusters (Figure 1C). Interestingly, Hes 1 transfection of neurons protected these cells from the neurotoxic effects of $A \beta$. Indeed, while oligomerization of $\mathrm{A} \beta$ (Figure S1A in Additional file 1) decreased the length and increased the number of primary dendrites, albeit decreasing GABAergic input, these effects were completely reversed by Hes 1 transfection (Figure 1A, $\mathrm{B}$ and $1 \mathrm{C})$. Moreover, Hes1 overexpression attenuated the effects of $A \beta$ on neuronal survival. Using a concentration of $5 \mu \mathrm{M} \mathrm{A} \beta(1-42)$ in these studies to ensure that most cells would die during the experiment (performed over $90 \mathrm{~h}$ (Figure S1B in Additional file 1), prior transfection with Hes 1 rescued $50 \%$ of neurons from this $A \beta$-induced death (Figure 1D). Taken together, these findings demonstrate that optimal expression of Hes 1 counteracts the effects of $A \beta$ on neurons at all the levels examined here.

\section{Activation of NF- $\kappa$ B blocks the effects of $A \beta$ on neuronal morphology and connectivity}

Having previously revealed that NGF augments Hes 1 by activating NF- $\kappa \mathrm{B}[13]$, the link between NF- $\kappa \mathrm{B}$ activation and Hes 1 expression was confirmed here using an alternative experimental approach. Cultured hippocampal neurons were transfected with a plasmid expressing p65/ RelA, and Hes 1 expression was assessed by quantitative PCR. Although only 20 to $25 \%$ of neurons were transfected, a significant increase (35 to 40\%) in Hes 1 mRNA was evident throughout the culture (Figure 2A). Transfected, myc-tagged p65/RelA was predominantly found in the nucleus, as expected given its capacity to promote Hes 1 expression (Figure 2B). Moreover, p65/RelA overexpression produced marked changes in dendrite arborisation, increasing the length and decreasing the number of primary dendrites (Figure 2B). These effects were paralleled by a substantial increase in GABAergic connectivity (Figure 2B, D) concomitant with an increase in Hes 1 expression (Figure 1). As seen following Hes 1 transfection, p65/RelA transfection blocked the effects of $A \beta$ on both dendrite morphology and connectivity, preventing the increase in dendrite length and the decrease in dendrite number induced by $\mathrm{A} \beta$ (Figure $2 \mathrm{~A}, \mathrm{~B}$ and $2 \mathrm{C}$ ).
Indeed, p65/RelA overexpression also prevented the decrease in VIAAT-positive terminals induced by $A \beta$. The anti-amyloid effects of p65/RelA overexpression on neuronal survival could not be studied, as p65/RelA overexpression induced neuronal death two days after transfection (that is, before $A \beta$ had noxious effects on cultured neurons).

\section{IKK $\beta$ activation counteracts the effects of beta-amyloid}

NGF was shown to activate NF- $\kappa$ B via tyrosine phosphorylation and the subsequent degradation of I- $\kappa \mathrm{B} \alpha$ [12]. The canonical NF- $\kappa$ B activation pathway involves $\operatorname{Ser}(32,36)$ phosphorylation of $\mathrm{I}-\kappa \mathrm{B} \alpha$ catalysed by the IKKs, and hence we tested whether increased activity of IKK proteins conferred amyloid resistance to cultured neurons. When cultured hippocampal neurons were transfected with a plasmid overexpressing IKK $\beta$, again only 20 to $25 \%$ of neurons were transfected (data not shown). Nonetheless, the levels of Hes1 mRNA increased significantly (25 to $30 \%)$ throughout the entire culture (Figure 3A). As expected, IKK $\beta$ overexpression produced similar alterations in neuronal morphology as Hes 1 or p65/RelA transfection (longer and fewer dendrites) (Figure $3 \mathrm{~B}$ ). In addition, IKK $\beta$ transfection conferred hippocampal neurons with resistance to $A \beta$ (Figure $3 C$, left panel). These effects were specific to IKK $\beta$ as transfection with IKK $\alpha$ produced no noticeable changes in dendrites (not shown) and conferred only very modest resistance to $A \beta$ neurotoxicity (Figure 3C, right panel).

\section{Effects of TGF $\beta 1$ on neuronal morphology, connectivity and survival}

Based on the changes observed in dendrite morphology, and in neuronal connectivity and survival following Hes 1 overexpression, we investigated the effects of an alternative means of activating $\mathrm{NF}-\kappa \mathrm{B}$ using the cytokine TGF $\beta 1$ [22]. The role of TGF $\beta 1$ in neuronal polarity and axonal specification has been studied previously [23], and while TGF $\beta 1-3$ promote dendrite growth in retinal ganglion cells [24], the effects of TGF $\beta$ on neuronal plasticity remain unclear. We first studied the effects of TGF $\beta 1$ on dendritic patterning in cultured hippocampal neurons after 7 DIV. Exposure to TGF $\beta 1$ increased the number of primary dendrites while decreasing the number of remaining dendrites (Figure 4A). Moreover, GABAergic connectivity was augmented in cultured hippocampal neurons treated with TGF $\beta 1$, as revealed by VIAAT immunostaining (Figure 4A, right panel). Varicosities containing VIAAT also increased upon TGF $\beta 1$ administration. The effects of TGF $\beta 1$ were mediated by Hes 1 as TGF $\beta 1$ had no such activity in neurons transfected with the Hes 1 inhibitor Hes6 $[19,20,25]$. Impairment of Hes 1 also prevented TGF $\beta 1$ from altering dendrite patterning and GABAergic connectivity. 

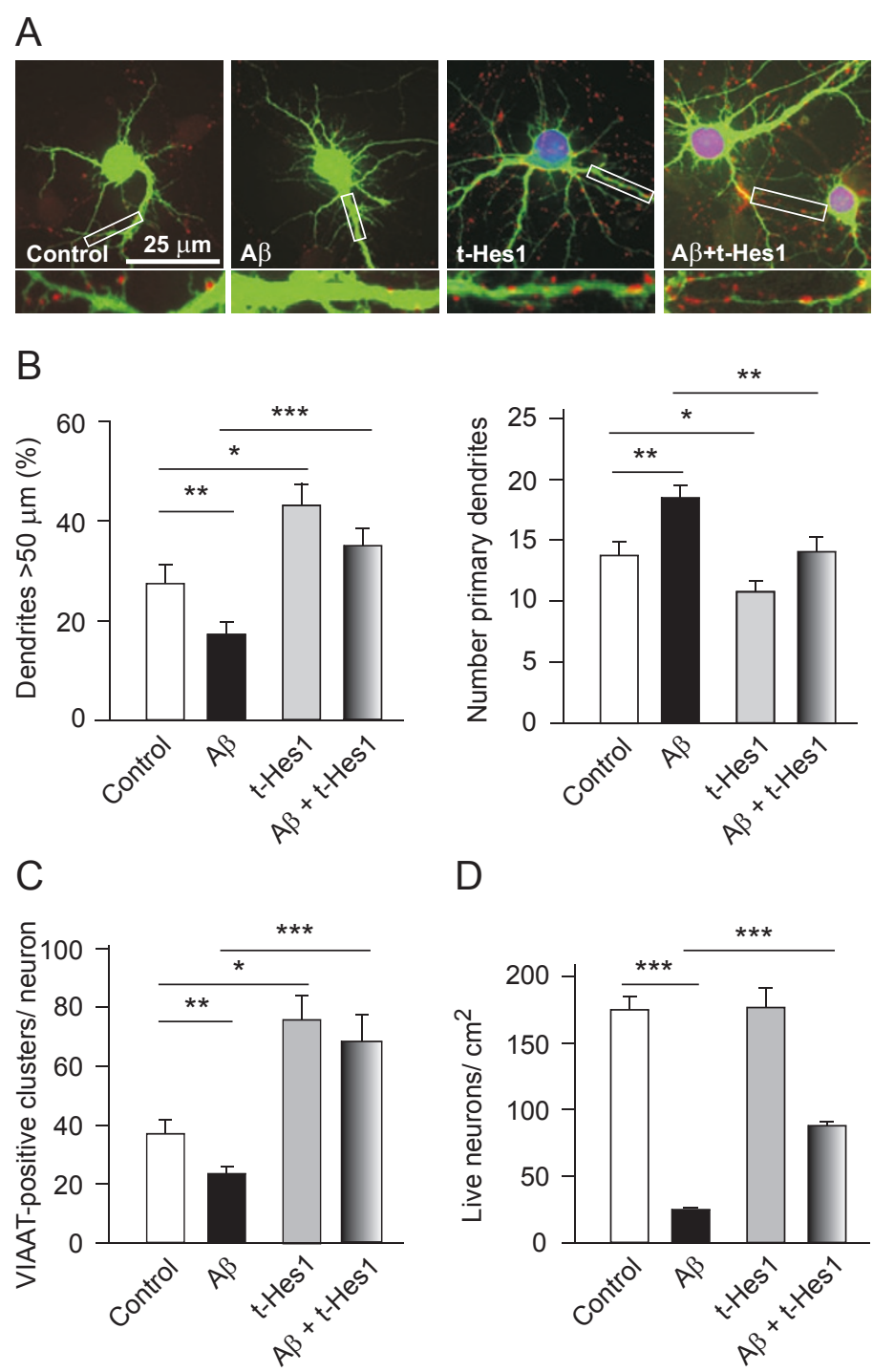

$\mathrm{D}$

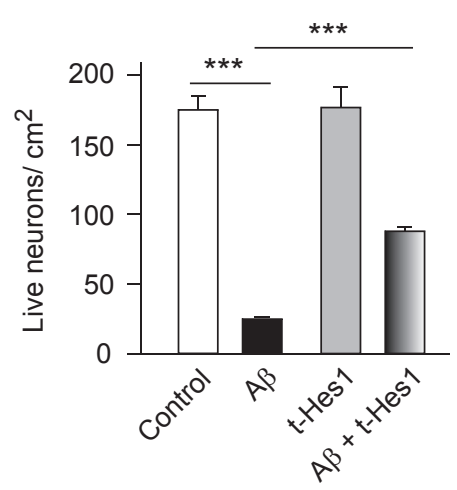

Figure 1 Hes 1 overexpression blocked the effects of amyloid beta (AB) on the morphology, GABAergic connectivity and survival of cultured hippocampal neurons. (A-C) E17 hippocampal neurons were plated at a density of $40,000 \mathrm{cells} / \mathrm{cm}^{2}$ and cultured for 7 days in vitro (DIV). Neurons were treated with $A \beta(5 \mu \mathrm{M})$, and/or they were co-transfected with enhanced green fluorescent protein (EGFP) and a myc-tagged Hes 1 vector for $16 \mathrm{~h}$. The cells were fixed and labeled with anti-EGFP, anti-myc and anti- vesicular inhibitory amino acid transporter (VIAAT) antibodies, and examined by immunofluorescence. (A) Representative micrographs of cultured neurons under different conditions. Nuclear labeling (in purple) corresponds to myc-tagged Hes1. Punctuated red dots correspond to VIAAT immunostaining. Lower panels show the boxed regions at higher magnification. (B) Morphometric analysis was performed as indicated in Materials and methods. Note that A $\beta$ decreased the length of primary dendrites (left panel) and increased their number (right panel), whereas Hes 1 induced opposite effects, counteracting those of $A \beta$. (C) Hes 1 overexpression increased the number of GABAergic terminals in cultured neurons, overriding the decrease induced by $A \beta$ administration. (D) 7 DIV neurons $\left(30,000\right.$ cells $\left./ \mathrm{cm}^{2}\right)$ were treated with $\mathrm{A} \beta(5 \mu \mathrm{M})$. Two days later the neurons were co-transfected with EGFP and the myc-tagged Hes 1 vector, and the cells were stained with anti-EGFP, anti-myc antibodies and 4',6-diamidino-2-phenylindole (DAPI) on the following day. EGFP and myc dual-labeled cells with intact nuclei were counted. Approximately $50 \%$ of transfected neurons survived $A \beta$ treatment. ${ }^{*} P<0.05,{ }^{*} P<0.01$, and ${ }^{* *} P<0.001$.

Although the TGF $\beta 1$ transduction pathway that modulates neuronal plasticity is poorly understood (but see Discussion), TGF $\beta 1$ is known to activate NF- $\kappa$ B in hippocampal neurons [22]. We found that this activation of $\mathrm{NF}-\kappa \mathrm{B}$ by TGF $\beta 1$ may be involved in neuronal plasticity, and thus we analyzed the morphological changes induced by TGF $\beta 1$ in cells transfected with either a non-serine phosphorylatable mutant I- $\kappa \mathrm{B} \alpha$ or a non-tyrosine phosphorylatable form of I- $\kappa \mathrm{B} \alpha$. Transfection with the serine mutant blocked the effects of TGF $\beta 1$ on dendrite elongation and GABAergic connectivity (Figure 4B), whereas transfection with the tyrosine mutant of $\mathrm{I}-\kappa \mathrm{B} \alpha$ had no 


\section{A}

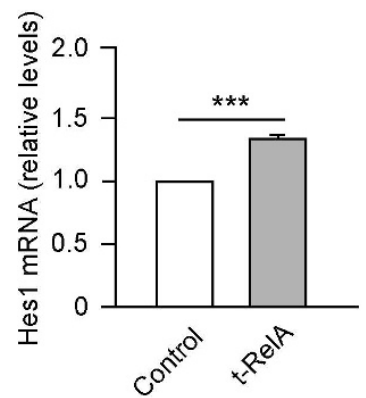

B
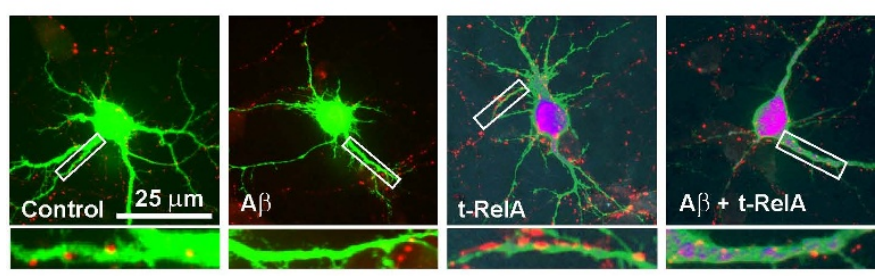

C
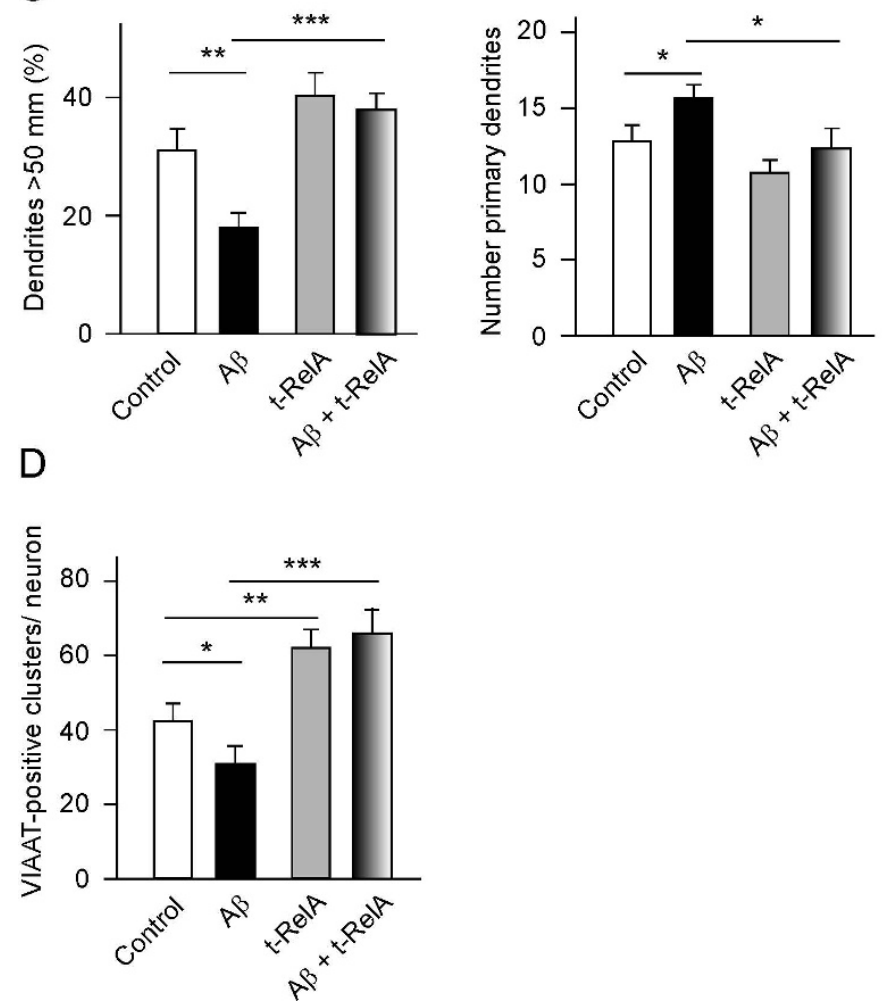

Figure 2 Transfection of p65/RelA promoted Hes 1 expression and counteracted the effects of amyloid beta (AB) on the morphology and GABAergic connectivity of cultured hippocampal neurons. (A) 7 days in vitro (DIV) neurons (300,000 cells) were transfected with a plasmid encoding myc-tagged p65/RelA. After 16 h, the cells were lysed and processed for real time-PCR, showing that Hes 1 expression levels increased by 35\%. (B-D) Cultured hippocampal neurons (40,000 cells/ $\mathrm{cm}^{2}, 7$ DIV) were co-transfected with enhanced green fluorescent protein (EGFP) and myc-p65/RelA plasmids, treated with $A \beta(5 \mu \mathrm{M})$ and incubated for a further $16 \mathrm{~h}$, before analyzing dendritic patterning (B, C) and GABAergic connectivity (B, D). (B) Representative micrographs of 7 DIV hippocampal neurons treated with A $\beta$ and/or transfected with p65/RelA. EGFP immunostaining (green) and the transfected p65/RelA mostly located to the nucleus (purple). Vesicular inhibitory amino acid transporter (VIAAT) was evident as punctuated red dots. Lower panels show the boxed regions at higher magnification. (C) Morphometric analysis of treated neurons. p65/RelA overexpression increased the length (left panel) but decreased the number (right panel) of primary dendrites, thereby counteracting the effects of $A \beta$. (D) p65/RelA overexpression increased the number of GABAergic terminals in cultured neurons and overrode the decrease in GABAergic terminals produced by $A \beta$. ${ }^{*} P<0.05$, ${ }^{* *} P<0.01$, and ${ }^{* *} P<0.001$. 

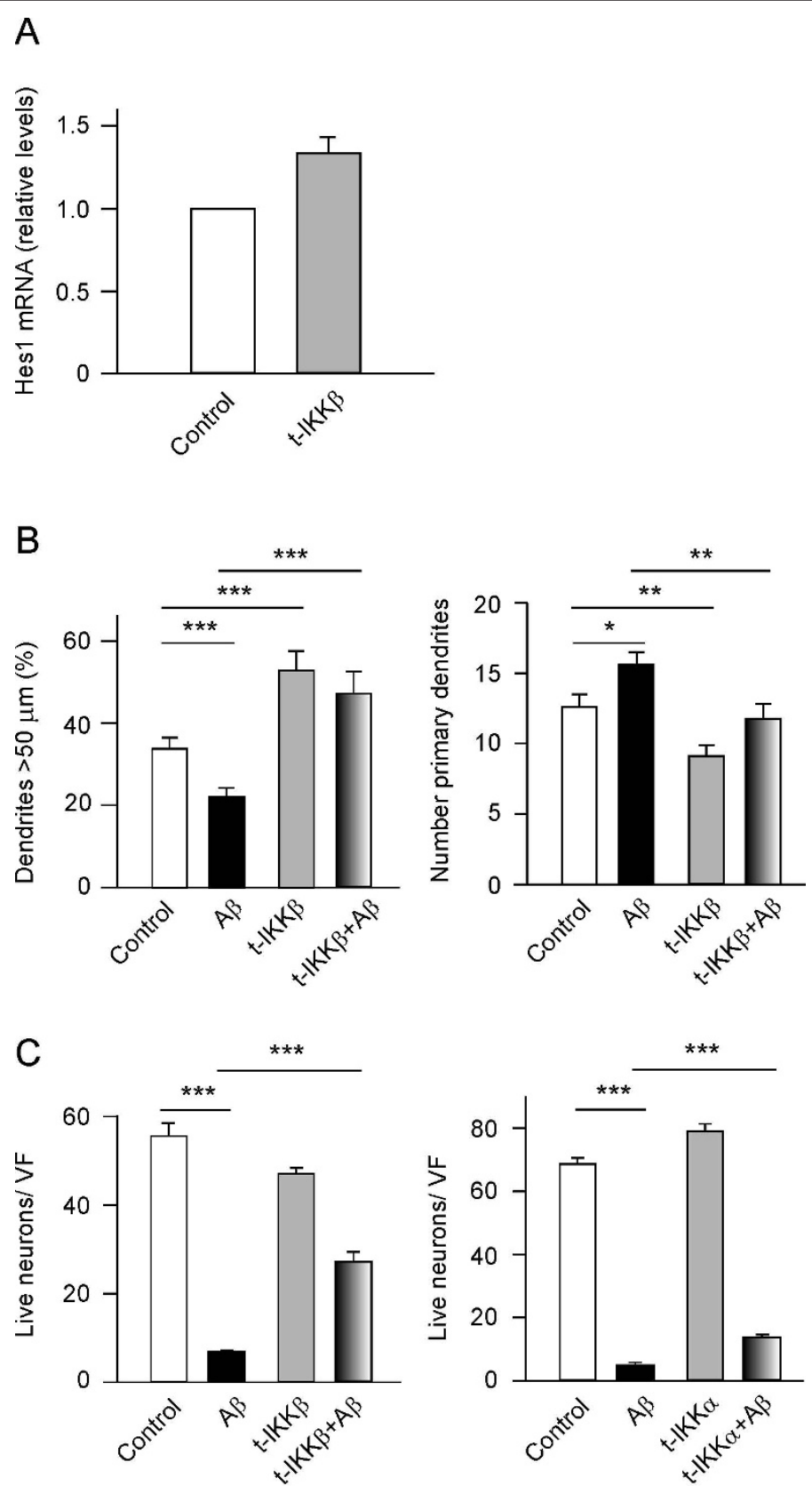

Figure $3 \mathrm{I}-\kappa \mathrm{B}$ kinase (IKK- $\beta$ ) induces Hes 1 expression, modulates dendritic morphology and neuronal survival, and it counteracts amyloid beta (A $\boldsymbol{\beta}$ ) activity. (A) The efficiency of transfecting 7 days in vitro (DIV) cultured neurons $(300,000$ cells) with a vector expressing Flagtagged IKK $\beta$ was 20-25\%. After $16 \mathrm{~h}$, the cells were lysed and Hes 1 expression was quantified by real time PCR, and transfection of IKK $\beta$ increased Hes-1 mRNA levels by 35\%. (B) Hippocampal neurons were cultured for 7 DIV $\left(40,000 \mathrm{cells} / \mathrm{cm}^{2}\right)$, treated with A $(5 \mu \mathrm{M})$, and/or cotransfected with enhanced fluorescent green protein (EGFP) and FLAG-tagged IKK- $\beta$ for 16 h. Transfection with IKK $\beta$ increased the length (left panel) but decreased the number (right panel) of primary dendrites, and blocked the effect of A $\beta$ on dendrite morphology. (C) 7 DIV hippocampal neurons $\left(30,000\right.$ cells $\left./ \mathrm{cm}^{2}\right)$ were cultured for 7 days and then treated with $A \beta(5 \mu \mathrm{M})$. Two days later, the neurons were cotransfected with EGFP, FLAG-tagged IKKK and/or HA-tagged IKK $\alpha$ and the number of live cells was determined on the following day. IKK $\beta$ transfection rescued about $50 \%$ of neurons from $A \beta$-induced death (left panel), whereas this rescue was more modest when neurons were transfected with IKK $\alpha$ rather than IKK $\beta$ (right panel). ${ }^{*} P<0.05$, ${ }^{* *} P<0.01$, and ${ }^{* * *} P<0.001$.

effect on TGF $\beta 1$ activity. Accordingly, the effects of TGF $\beta 1$ on neuronal plasticity are dependent upon serine phosphorylation of I- $\kappa \mathrm{B}$ and its capacity to activate NF- $\kappa \mathrm{B}$. By contrast, overexpression of the tyrosine mutant form had no effect on TGF $\beta 1$ activity (Figure 4B). In conjunction with previous findings [12], these results suggest 

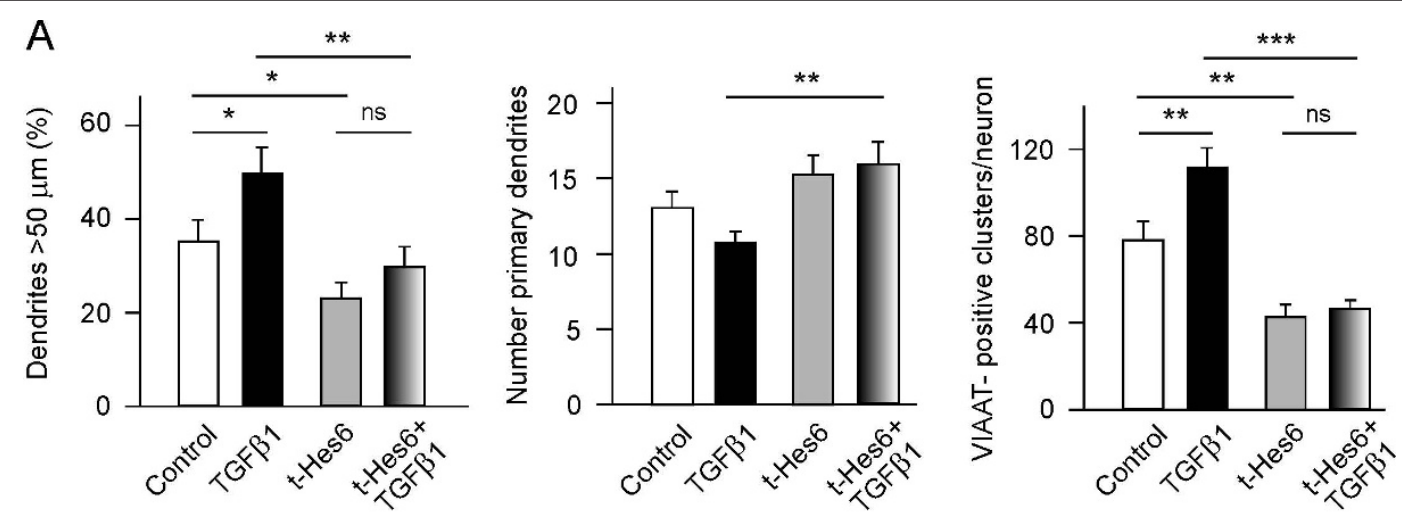

B
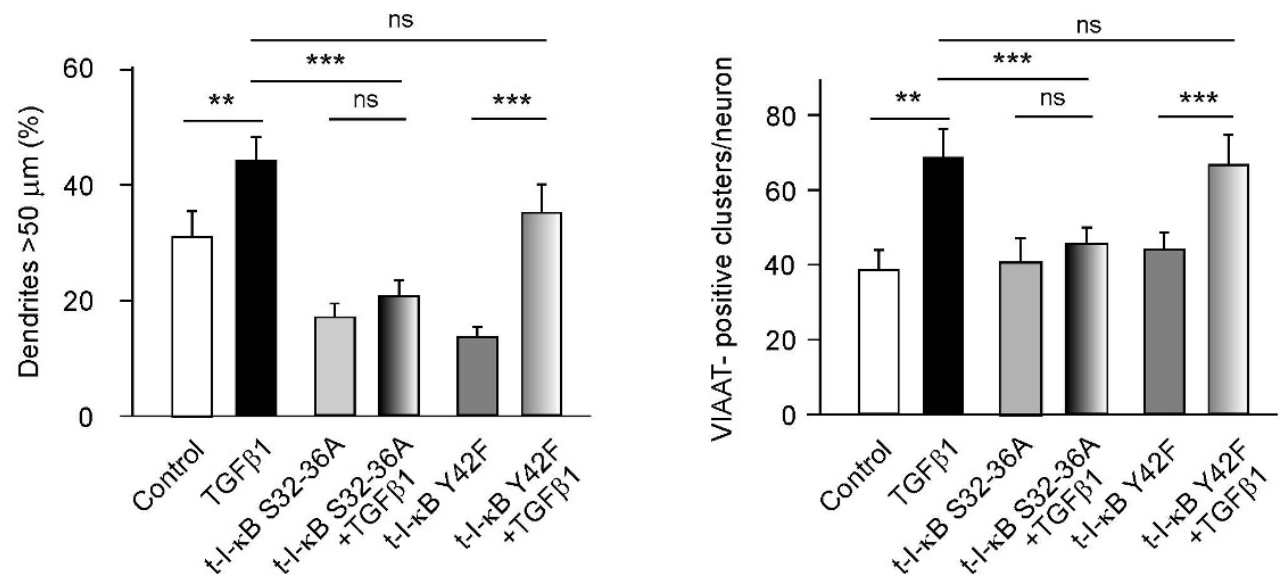

Figure 4 Transforming growth factor $\beta 1$ (TGF $\beta 1$ ) controls dendrite morphology and neuronal connectivity via I- $\kappa$ B $\alpha$ and Hes 1 . Hippocampal neurons (7 days in vitro (DIV), 40,000 cells/ $\left.\mathrm{cm}^{2}\right)$ were treated with TGF $\beta 1(10 \mathrm{ng} / \mathrm{ml})$ before they were co-transfected with pEGFP and plasmids overexpressing either myc-tagged Hes6 (A) or mutant forms of FLAG-tagged I- $\kappa \mathrm{B} \alpha(\mathbf{B})$ for $16 \mathrm{~h}$. The neurons were then processed for immunocytochemistry using anti-EGFP and anti-myc/anti-FLAG antibodies. (A) Overexpression of Hes6, a known inhibitor of Hes 1, abrogated the effects of TGF $\beta 1$ on dendritic length (left panel) and on the number of primary dendrites (middle panel). Hes 6 overexpression also prevented the TGF $\beta 1$-induced increase in the number of GABAergic terminals (right panel). (B) Transfection of I- $\kappa$ B $\alpha$ S32-36A (a mutation that affects serine phosphorylation of the inhibitor) prevented the TGF $\beta 1$-induced increase in dendritic length (left panel) and attenuated the formation of vesicular inhibitory amino acid transporter (VIAAT)-positive clusters (right panel). The $1-\kappa \mathrm{B} \alpha \mathrm{Y} 42 \mathrm{~F}$ mutation that affects the tyrosine phosphorylation of the inhibitor had no effect on TGF $\beta 1$ activity. ${ }^{*} P<0.05,{ }^{* *} P<0.01$, and ${ }^{* * *} P<0.001$

that Hes1 can be activated by either NGF or TGF 1 . Both these factors activate $\mathrm{NF}-\kappa \mathrm{B}$, although the former degrades I- $\kappa \mathrm{B} \alpha$ by phosphorylation at tyrosine 42 [12] and the latter by phosphorylating serines 32 and 36 .

\section{Anti-amyloid effects of TGF $\beta 1$}

As $A \beta$ prevents NGF-induced tyrosine phosphorylation and the subsequent degradation of I- $\kappa \mathrm{B} \alpha$ [12], we asked whether TGF $\beta 1$ could counteract the noxious effects of $\mathrm{A} \beta$ by activating NF- $\kappa \mathrm{B}$ after having promoted serine phosphorylation of $\mathrm{I}-\kappa \mathrm{B} \alpha$. Using a reporter gene luminescent assay, we demonstrated that TGF $\beta 1$ activated NF- $\kappa \mathrm{B}$ (Figure $5 \mathrm{~A}$ ), more than doubling its activity in cultured neurons. Moreover, the reporter gene assay revealed a modest but significant decrease in NF- $\kappa \mathrm{B}$ activity produced by $A \beta$, which significantly failed to prevent TGF $\beta 1$-induced activation of NF- $\kappa \mathrm{B}$. In accordance with this observation, we found that TGF $\beta 1$ increased neuronal Hes 1 mRNA expression, while A $\beta$ induced a significant reduction in Hes1 expression (Figure $5 \mathrm{~B}$ ). Indeed, exposure to TGF $\beta 1$ partially restored the low levels of Hes 1 expression induced by $\mathrm{A} \beta$. These results demonstrate that TGF $\beta 1$ opposes the effects of $\mathrm{A} \beta$ on NF- $\kappa \mathrm{B}$ activation and Hes 1 expression.

Based on the above findings, we examined the anti-amyloid effects of TGF $\beta 1$ on neuronal morphology, connectivity and survival (Figure 5C-F). TGF $\beta 1$ blocked the effects of $\mathrm{A} \beta$ on dendrite length and number (Figure $5 \mathrm{C}, \mathrm{D}$ ), and it prevented the $A \beta$-induced decrease in the number of GABAergic terminals (Figure 5C, E). Finally, administration of TGF $\beta 1$ to cultured neurons protected about $50 \%$ of neurons from $A \beta$ neurotoxicity Figure 5F). These 

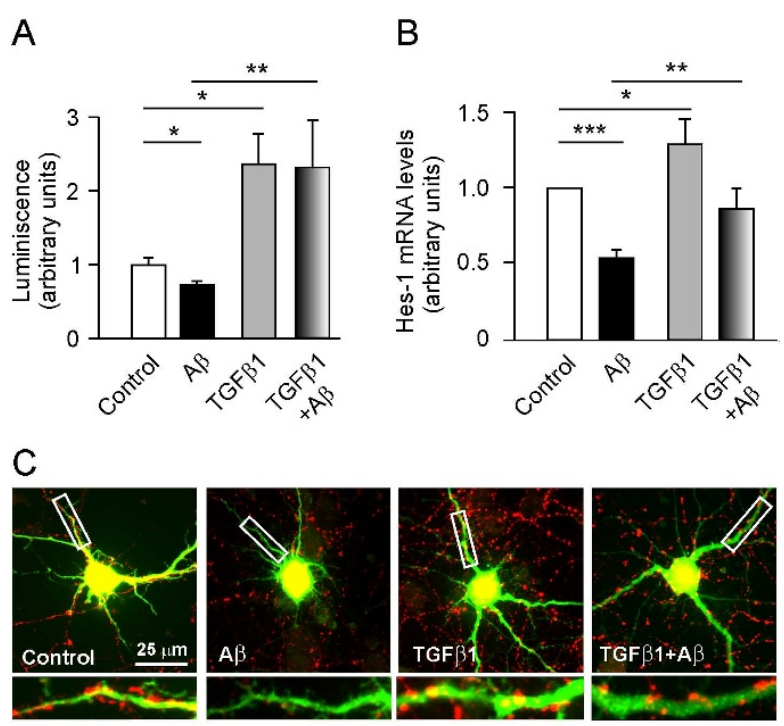

\section{D}
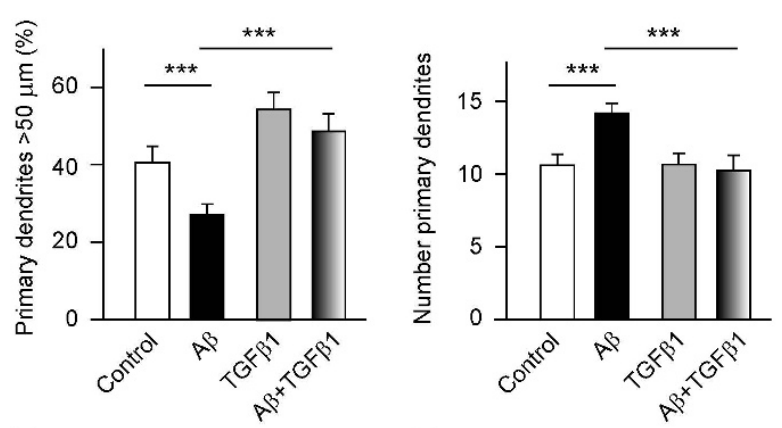

E

$\mathrm{F}$
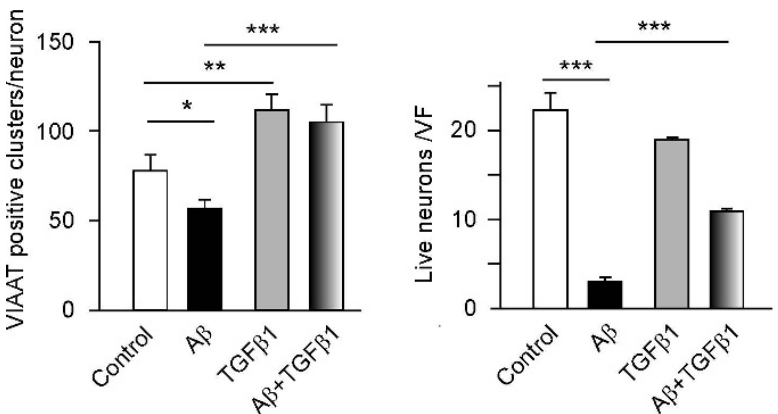

Figure 5 Tranforming growth factor $\beta 1$ (TGF $\beta 1$ ) activates nuclear factor kappa-B (NF- $\kappa \mathrm{B}$ ) and induces Hes 1 expression, controlling dendrite morphology and GABAergic connectivity, and conferring cultured neurons with resistance to amyloid beta ( $A \beta$ ) neurotoxicity.

(A) Dual-luciferase NF- $\kappa$ B reporter gene assay. After transfecting NF- $\kappa$ B-luc and RL-TK-luc, 7 days in vitro (DIV) hippocampal neurons were incubated for $16 \mathrm{~h}$ and the neurons were then exposed to $A \beta(5 \mu \mathrm{M})$ with TGF $1(10 \mathrm{ng} / \mathrm{ml})$ added to the medium $1 \mathrm{~h}$ later. The neurons were analyzed after a further $4 \mathrm{~h}$ incubation and the data represent the means of six experiments. (B) Cultured neurons (7 DIV, 300,000 cells) were treated with A $(5 \mu \mathrm{M})$ and then TGF $\beta 1(10 \mathrm{ng} / \mathrm{ml}) 1 \mathrm{~h}$ later, and the cells incubated for a further $16 \mathrm{~h}$. After lysing the cells, Hes 1 expression was quantified by real time PCR (the means of 10 determinations are shown). (C-E) Hippocampal neurons (7 DIV, 40,000 cells/cm²) were transfected with enhanced green fluorescent protein (EGFP) and treated with $A \beta(5 \mu \mathrm{M})$ and/or TGF $\beta 1(10 \mathrm{ng} / \mathrm{ml})$. After $16 \mathrm{~h}$, immunostaining for EGFP and vesicular inhibitory amino acid transporter (VIAAT) was performed as described in Materials and methods. (C) Representative micrographs of cultured neurons under different conditions (the lower panels show the boxed regions at higher magnification). (D) Morphometric analysis of A $\beta$ - and TGF $\beta$ 1-treated neurons. TGF $\beta 1$ increased the length (left panel) and decreased the number (right panel) of primary dendrites, thereby counteracting the effects of $A \beta$. (E) Quantification of GABAergic clusters. TGF $\beta 1$ increased the number of GABAergic terminals in cultured neurons and overrode the decrease in GABAergic terminals induced by $A \beta$. (F) Hippocampal neurons (7 DIV, 30,000 cells/ $\mathrm{cm}^{2}$ ) were treated with A $\beta(5 \mu \mathrm{M})$ and/or TGF $\beta 1$ (10 ng/ml) for $90 \mathrm{~h}$ and the number of intact nuclei were counted after 4,6-diamidino-2-phenylindole (DAPI) staining. TGF $\beta 1$ prevented A 3 -induced death of a portion of cultured hippocampal neurons. ${ }^{*} P<0.05$, ${ }^{*} P<0.01$, and ${ }^{* * *} P<0.001$. 
results emphasize the potential of TGF $\beta 1$ as a neuroprotective agent and reveal, at least in part, the molecular basis of this neuroprotective activity.

\section{Discussion}

The effect of NF- $\kappa$ B activity on neuron survival

Transcription factors, including NF- $\kappa \mathrm{B}$, are implicated in experience-based synaptic regulation, and mouse models involving altered NF- $\kappa \mathrm{B}$ activity have revealed the importance of the various forms of this transcription factor in learning and memory (reviewed in [26]). NF- $\kappa \mathrm{B}$ may influence neuronal plasticity at multiple levels as it mediates neurite outgrowth [27] and participates in the development of dendritic spines [28]. NF- $\kappa \mathrm{B}$ also plays an important role in the dendritic development of Purkinje cells, since when it is inhibited with a lysyl oxidase peptide, serious deficits in dendritic arborisation are provoked [29]. Here, we show that p65/RelA transfection induces significant changes in the morphology of the dendrites emitted by cultured hippocampal neurons. These alterations were similar to those previously described for NGF, the effects of which are partially mediated by NF- $\kappa$ B [13]. Overexpression of p65/RelA induces an increase in dendritic length and a decrease in dendrite number within $16 \mathrm{~h}$. Perhaps more importantly, p65/RelA overexpression counteracts the effects of $A \beta$ on dendrite morphology, decreasing dendrite length and increasing the number of primary dendrites. This finding provides an important indication of the anti-amyloid effects of p65/RelA overexpression.

NF- $\kappa \mathrm{B}$ exerts neuroprotective effects against some neurotoxic agents [30,31], including $A \beta$ [32], and total abrogation of NF- $\kappa \mathrm{B}$ activation by pharmacological agents was followed by hippocampal neuron death (Figure S2A in Additional file 2). However, with the exception of bcl-XL induction [33] and the suppression of apoptotic proteins such as Bax and Bim [34], the mechanisms underlying $\mathrm{NF}-\kappa \mathrm{B}$-induced neuroprotection remain elusive. In neurons, NF- $\kappa \mathrm{B}$ is required to maintain high GluR1 levels and neuronal hyperexcitability following the induction of longterm potentiation (LTP) [35]. However, increases in $\mathrm{NF}-\kappa \mathrm{B}$ activity in response to enhanced excitatory transmission may accelerate the onset of the cognitive defect in a mouse model of Alzheimer's disease [36]. The present results show that $\mathrm{p} 65 /$ RelA promotes GABAergic connectivity in cultured hippocampal neurons, as revealed by the substantial increases in terminals containing VIAAT. We previously reported a substantial loss of VIAAT-labeled terminals shortly after $A \beta$ administration in cultured hippocampal neurons [12] These effects were fully prevented by overexpressing p65/RelA, which may explain the basis underlying the anti-amyloid activity of NF- $\kappa \mathrm{B}$.

Together with inhibitors of NF- $\kappa$ B kinases, NF- $\kappa$ B regulates many physiological responses, and activation of
IKK in neurons should induce similar cellular changes to those elicited by p65/RelA overexpression. The canonical pathway of NF- $\kappa$ B activation involves I- $\kappa \mathrm{B} \alpha$ phosphorylation via activation of the IKK complex (reviewed in [37]). Transfection of hippocampal neurons with a plasmid expressing IKK $\beta$ promoted dendritic growth while decreasing the number of primary dendrites. Furthermore, IKK $\beta$ transfection prevented $A \beta$ from altering dendritic patterning. Most importantly, IKK $\beta$ overexpression protected a significant number of neurons from the deleterious effects of $\mathrm{A} \beta$. Thus, canonical activation of NF$\kappa \mathrm{B}$ conferred amyloid resistance to cultured hippocampal neurons.

\section{The role of Hes1 in anti-amyloid neuroprotection}

Hes 1 is an important target of IKK $\beta / N F-\kappa B$ in terms of its influence on neuronal morphology and survival. Activation of NF- $\kappa \mathrm{B}$ by NGF increases Hes 1 expression, whereas specific inhibition of this nuclear factor abrogates the activity of the neurotrophin $[12,13]$ and it eventually caused cell death (Figure S2A in Additional file 2). We found that overexpression of either IKK $\beta$ or p65/ RelA induces an increase in Hes 1 expression in transfected hippocampal neurons. To further demonstrate that both the morphological and anti-amyloid effects of IKK $\beta$ and p65/RelA depend upon Hes 1 expression, we transfected neurons with a vector that drives the overexpression of this gene. Hes 1 overexpression induced the same morphological changes as seen following IKK $\beta$ or p65/RelA overexpression, including a large increase in GABAergic connectivity. As expected, Hes1 overexpression counteracted the effects of $A \beta$ on cell morphology and GABAergic terminals, and strikingly, overexpression of Hes 1 also rescued $50 \%$ of neurons from $A \beta$-induced death. Conversely, inhibition of Hes 1 activity by overexpression of Hes6 induced cell death (Figure S2B in Additional file 2). Together, these findings indicate that correct expression of Hes 1 confers anti-amyloid resistance to cultured hippocampal neurons, strongly suggesting that strategies to increase Hes 1 expression and activity may protect neurons from $A \beta$ toxicity.

\section{TGF $\beta 1$ provides an alternative means of promoting Hes 1 expression and inducing anti-amyloid activity}

TGF $\beta 1$ has long been recognized as a neuroprotective agent (for a review see [38]) and indeed, neurodegeneration $[39,40]$ and $A \beta$ deposition $[41]$ are enhanced in TGF $\beta 1$ deficient mice. Furthermore, components of the hippocampal TGF $\beta$ pathway are altered in schizophrenia and psychiatric disorders [42]. Several TGF $\beta$ signalling pathways have been elucidated [43] and the canonical pathway involves the activation and nuclear localization of the Smad complex, where it modulates target gene transcription. However, our data suggest that the neuroprotective 
activity of TGF $\beta 1$ is not mediated by this canonical pathway but rather, by NF- $\kappa \mathrm{B} /$ Hes 1 . Administration of TGF $\beta 1$ to cultured neurons alters dendritic patterning and GABAergic connectivity in a manner consistent with Hes 1 overexpression. Moreover, transfection with Hes6, an inhibitor of Hes 1 transcriptional activity [19,20,25], abrogated all the effects of TGF $\beta 1$ on neuronal morphology and connectivity. Although Hes1 upregulation by TGF $\beta 1$ has been reported previously in fibroblasts [44], this is the first time the regulation of this bHLH gene by TGF $\beta 1$ has been described in hippocampal neurons.

Further assays of neuronal morphology and connectivity revealed the involvement of I- $\kappa \mathrm{B} \alpha$ in TGF $\beta 1$ signalling. Transfection with a serine mutant form of I- $\kappa \mathrm{B} \alpha$ abolishes the effects of TGF $\beta 1$ on both dendritic shape and on the number of GABAergic terminals. However, a tyrosine mutant form of I- $\kappa \mathrm{B} \alpha$ had no effect on TGF $\beta 1$ activity, indicating that serine phosphorylation of I- $\kappa \mathrm{B} \alpha$ preceded NF- $\kappa$ B activation in this pathway. Direct biochemical measurements revealed that treatment of cultured neurons with TGF $\beta 1$ promoted NF- $\kappa \mathrm{B}$ activation and Hes 1 expression. The activation of NF- $\kappa \mathrm{B}$ by TGF $\beta 1$ has been reported previously in cultured hippocampal neurons from rat embryos [22]. However, we also observed that TGF $\beta 1$ reversed the loss in NF- $\kappa \mathrm{B}$ activity and Hes 1 expression induced by $A \beta$. Indeed, TGF $\beta 1$ also prevented the formation of VIAAT-positive clusters in response to $\mathrm{A} \beta$, and it prevented $\mathrm{A} \beta$ from altering dendrite patterning. Most importantly, TGF $\beta 1$ rescued a significant portion of neurons from $A \beta$-induced death. These findings confirm the neuroprotective capacity of this cytokine and the underlying role of NF- $\kappa \mathrm{B}$ activation and Hes1 expression.

We showed previously that the action of $A \beta$ is exerted in part by inhibiting early steps in the NGF signalling pathway, including the deactivation of RhoA and the activation of PTP1B, both events that are needed for NF- $\kappa \mathrm{B}$ activation and to promote Hes 1 expression [15]. Accordingly, TGF $\beta 1$ can circumvent such effects by activating NF- $\kappa \mathrm{B}$ through an alternative mechanism that involves the serine phosphorylation of $\mathrm{I}-\kappa \mathrm{B}$, as shown here. However, when NF- $\kappa \mathrm{B}$ activation was pharmacologically impaired by $\mathrm{SN}-50$ or when Hes 1 activity was blocked by Hes 6 overexpression, TGF $\beta 1$ activity was abrogated (Figure S2A and S2B in Additional file 2). Together, these results suggest that on the one hand, NF- $\kappa \mathrm{B}$ activation and Hes1 activity are needed for cell survival, and on the other, that TGF $\beta 1$ exert its anti-amyloid activity by potentiating NF- $\kappa \mathrm{B}$ and Hes1 activities.

\section{Modulation of GABAergic input in neuroprotection}

Growth factors may control synaptic development and transmission in quantitative terms. Brain-derived neurotrophic factor (BDNF) upregulates glutamatergic input and downregulates the number of GABAergic synaptic terminals [45], while insulin promotes the postsynaptic accumulation of $\mathrm{GABA}_{\mathrm{A}}$ receptors by increasing Aktmediated phosphorylation of $\beta$ subunits (reviewed in [46]). NGF also increases the expression of GABAergic terminals in cultured hippocampal neurons, an effect mediated by altering Hes1 expression [13]. Via the canonical pathway involving Smad4, TGF $\beta 1$ is a critical factor in use-dependent modulation of $\mathrm{GABA}_{\mathrm{A}}$-mediated synaptic transmission and dendrite homeostasis [47].

In all experimental paradigms assayed here, including the transfection of cultured neurons with IKK $\beta, \mathrm{I} \kappa$-B $\alpha$ or p65/RelA and the exposure of cultured neurons to TGF $\beta 1$, VIAAT immunocytochemistry indicated that there was a large increase in the expression of GABAergic terminals. These experimental approaches also consistently prevented $A \beta$ from affecting GABAergic terminals, since exposure to $A \beta$ decreases the number of GABAergic connections after $16 \mathrm{~h}$ and kills cells after $90 \mathrm{~h}$. Thus, there is compelling evidence that Hes1 is an important element in the maintenance of GABAergic connectivity, although the mechanisms underlying this phenomenon remain unknown. The increase in GABAergic input promoted by NF- $\kappa \mathrm{B} /$ Hes 1 may provide a negative feedback in the control of excitatory activity and consequently, protect neurons from excitotoxicity. The increase in inhibitory activity induced by $\mathrm{NF}-\kappa \mathrm{B}$

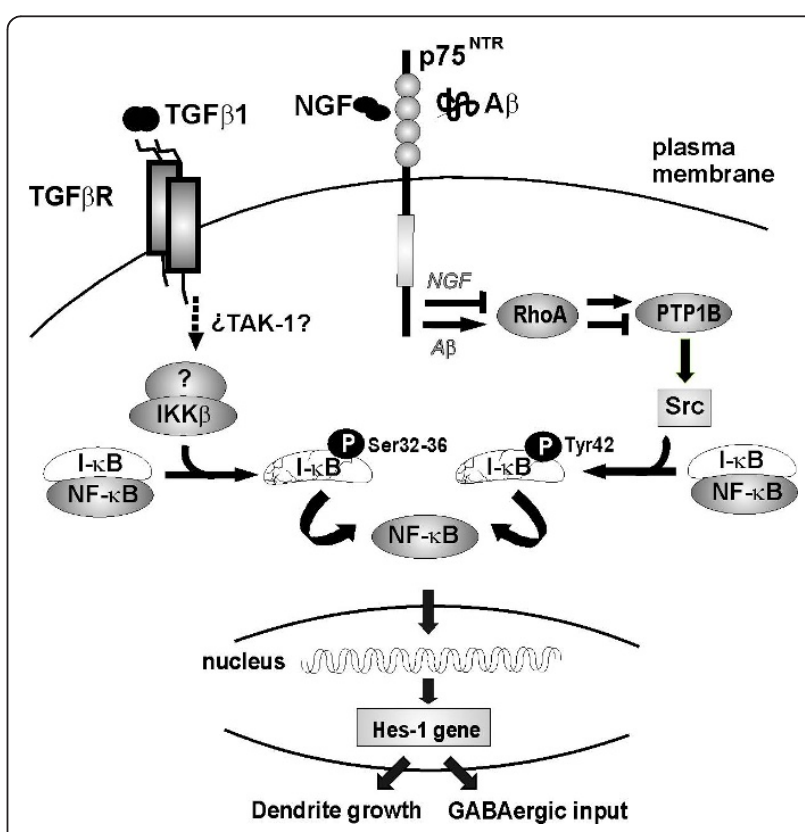

Figure 6 Transforming growth factor $\beta 1$ (TGF $\beta 1$ ), nerve growth factor (NGF) and amyloid beta (A $\beta$ )-induced signaling in hippocampal neurons. Diagram outlining the signal transduction pathways downstream of TGF $\beta 1$ that promote Hes 1 expression and neuronal survival. How NGF is impaired by $A \beta$ is also illustrated. In contrast to NGF, the activation of NF- $\kappa \mathrm{B}$ and the increased expression of Hes 1 induced by TGF $\beta 1$ are not inhibited by $A \beta$. 
activation or TGF $\beta 1$ administration may account for the neuroprotective effects observed. Indeed, TGF $\beta 1$ plays an important role in the excitatory/inhibitory balance of hippocampal transmission [47].

\section{Conclusions}

The findings presented here support the notion that neurons can be protected from the noxious effects of $A \beta$ by modulating inhibitory transmission. Moreover, strategies that mildly activate NF- $\kappa \mathrm{B}$ and/or that enhance Hes 1 expression could provide beneficial neuroprotection. Significantly, TGF $\beta 1$ signalling counteracts the inhibitory effect of $A \beta$ on NGF signalling (summarized in Figure 6), possibly supplementing the attenuated activity of NGF in Alzheimer's disease and representing a potential target for the development of anti-amyloid therapies.

\section{Additional material}

Additional file 1: Figure showing molecular characterization and neurotoxic properties of the amyloid $\beta(A \beta)$ preparations used in this study. (A) The preparations of $A \beta$ were characterized in western blots probed with an anti-A $\beta$ antibody following Bis-Tris PAGE separation (see Methods). Lane (1) shows that the stock preparation mostly contained monomeric and dimeric species, with smaller quantities of trimeric and tetrameric forms. In lanes 2 to $5, A \beta$ was added to $35 \mathrm{~mm}$ culture dishes that containing one glass polylysine coated $2 \times 2 \mathrm{~cm}$ coverslip and $2 \mathrm{~mL}$ of medium at the concentrations indicated. After a three-day incubation at $37^{\circ} \mathrm{C}$, aliquots of the medium were taken and resolved by electrophoresis (supernatant, snt, lanes 2 and 3).

Simultaneously, the glass coverslips were washed with LDS sample buffer and the material released was also separated in the same gels (immobilized on glass, imm, lanes 4 and 5). Note that the incubation of amyloid favoured the formation of higher molecular weight forms, although most species were small oligomers and the larger aggregates, including fibrils, only represented a small fraction of the amyloid. (B) Hippocampal neurons (7 days in vitro (DIV) and 30,000 cells $/ \mathrm{cm}^{2}$ ) were treated with $A \beta$ as indicated. After $90 \mathrm{~h}$, the cells were fixed and stained with 4',6-diamidino-2-phenylindole (DAPI) to asses the integrity of their nuclei. Note that $A \beta(5 \mu \mathrm{M})$ produced a high rate of cell death, which justified the use of this concentration in further experiments. VF, microscope view field.

Additional file 2: Figure showing the nuclear factor kappa B (NF- $\kappa$ B) pathway and Hes1 activity are needed for the survival of neurons, while transforming growth factor $\beta 1$ (TGF $\beta 1$ ) is unable to rescue cells from death. E17 hippocampal neurons were plated at a density of 30,000 cells $/ \mathrm{cm}^{2}$ and cultured for 7 days in vitro (DIV). Neurons were (A) treated for $24 \mathrm{~h}$ with $\mathrm{SN}-50(5 \mu \mathrm{M})$ or with its control peptide in the presence or absence of TGF $\beta 1(10 \mathrm{ng} / \mathrm{ml})$. (B) Neurons were cotransfected with enhanced green fluorescent protein (EGFP) and a myctagged Hes6 vector for $48 \mathrm{~h}$ in the presence or absence of TGF $\beta 1$. The cells were fixed and labeled with anti-EGFP and anti-myc antibodies, while the integrity of their nuclei was assessed by 4',6-diamidino-2phenylindole (DAPI) staining. Note that the obliteration of either NF- $\kappa \mathrm{B}$ activation or Hes1 activity was followed by neuron death. The addition of TGF $\beta 1$ did not reverse these effects.

\section{Abbreviations}

$A \beta$ : amyloid beta; AD: Alzheimer's disease; Akt: acutely transforming retrovirus AKT8 in rodent T cell lymphoma; BDNF: brain-derived neurotrophic factor; bHLH: basic helix-loop-helix; DAPI: 4',6-diamidino-2-phenylindole; DMSO: dimethyl sulfoxide; EGFP: enhanced green fluorescent protein; FAM: 6-carboxy fluorescein; GABA: gamma-aminobutyric acid; GLU1: glutamate receptor 1; HRP: horseradish peroxidise; I-kBa: I kappa $\mathrm{Ba}$; Hes1: enhancer of split homolog 1; IKKB: I-KB kinase; LTP: Iong-term potentiation; NF-KB: nuclear factor kappa-B; NGF: nerve growth factor; PBS: phosphate-buffered saline; PFA: paraformaldehyde; PTP1B: protein tyrosine phosphatase 1B; PVDF: polyvinylidene difluoride; ROI: region of interest; TGF $\beta 1$ : transforming growth factor $\beta 1$; VIAAT: vesicular inhibitory amino acid transporter; wt: wild type.

\section{Acknowledgements}

P Chacon was supported by the Instituto de Salud Carlos III (Contratos PostDoctorales Sara Borrell). This work was financed by the Fundació La Caixa (grant BM05-184) and the Spanish Ministry of Education and Science (grants BFU2007-63033 and BFU2010-20995). We are indebted to Emmanuel Villanueva, Ángel J del Marco and Rosa M García-Mejías for technical assistance. We thank Dr Lisardo Boscá (Madrid, Spain) for providing the IKK plasmids, Dr Mayte Coyras (Madrid, Spain) for the p65/RelA plasmid, Dr Ryoichiro Kageyama (Kyoto, Japan) for the Hes1 plasmid, Dr Phil Jones (Cambridge, UK) for the Hes6 plasmid.

\section{Authors' contributions}

PJC and ART designed and performed research; PJC and ART analyzed data; PJC and ART wrote the paper. Both authors have read and approved the final manuscript.

\section{Competing interests}

The authors declare that they have no competing interests.

Received: 24 January 2012 Revised: 11 June 2012

Accepted: 31 July 2012 Published: 31 July 2012

\section{References}

1. Wilcock DM, Colton CA: Anti-amyloid-beta immunotherapy in Alzheimer's disease: relevance of transgenic mouse studies to clinical trials. $J$ Alzheimers Dis 2008, 15:555-569.

2. Foster JK, Verdile G, Bates KA, Martins RN: Immunization in Alzheimer's disease: naive hope or realistic clinical potential? Mol Psychiatry 2009, 14:239-251.

3. St George-Hyslop PH, Morris JC: Will anti-amyloid therapies work for Alzheimer's disease? Lancet 2008, 372:180-182.

4. De Rosa R, Garcia AA, Braschi C, Capsoni S, Maffei L, Berardi N, Cattaneo A: Intranasal administration of nerve growth factor (NGF) rescues recognition memory deficits in AD11 anti-NGF transgenic mice. Proc Natl Acad Sci USA 2005, 102:3811-3816.

5. Louzada PR, Lima AC, Mendonca-Silva DL, Noel F, De Mello FG, Ferreira ST: Taurine prevents the neurotoxicity of beta-amyloid and glutamate receptor agonists: activation of GABA receptors and possible implications for Alzheimer's disease and other neurological disorders. FASEB J 2004, 18:511-518.

6. Louzada PR Jr, Paula Lima AC, De Mello FG, Ferreira ST: Dual role of glutamatergic neurotransmission on amyloid beta(1-42) aggregation and neurotoxicity in embryonic avian retina. Neurosci Lett 2001, 301:59-63.

7. Tuszynski MH, Blesch A: Nerve growth factor: from animal models of cholinergic neuronal degeneration to gene therapy in Alzheimer's disease. Prog Brain Res 2004, 146:441-449.

8. Tuszynski MH, Thal L, Pay M, Salmon DP, U HS, Bakay R, Patel P, Blesch A, Vahlsing HL, Ho G, Tong G, Potkin SG, Fallon J, Hansen L, Mufson EJ, Kordower JH, Gall C, Conner J: A phase 1 clinical trial of nerve growth factor gene therapy for Alzheimer disease. Nat Med 2005, 11:551-555.

9. Tuszynski MH: Nerve growth factor gene therapy in Alzheimer disease. Alzheimer Dis Assoc Disord 2007, 21:179-189.

10. Yaar M, Zhai S, Pilch PF, Doyle SM, Eisenhauer PB, Fine RE, Gilchrest BA: Binding of beta-amyloid to the $p 75$ neurotrophin receptor induces apoptosis. A possible mechanism for Alzheimer's disease. J Clin Invest 1997, 100:2333-2340

11. Yaar M, Zhai S, Fine RE, Eisenhauer PB, Arble BL, Stewart KB, Gilchrest BA: Amyloid beta binds trimers as well as monomers of the $75-\mathrm{kDa}$ neurotrophin receptor and activates receptor signaling. J Biol Chem 2002, 277:7720-7725.

12. Arevalo MA, Roldan PM, Chacon PJ, Rodriguez-Tebar A: Amyloid $\beta$ serves as an NGF-like neurotrophic factor or acts as a NGF antagonist depending on its concentration. J Neurochem 2009, 111:1425-1433. 
13. Salama-Cohen P, Arevalo MA, Meier J, Grantyn R, Rodriguez-Tebar A: NGF controls dendrite development in hippocampal neurons by binding to p75NTR and modulating the cellular targets of Notch. Mol Biol Cell 2005, 16:339-347.

14. Salama-Cohen P, Arevalo MA, Grantyn R, Rodriguez-Tebar A: Notch and NGF/p75NTR control dendrite morphology and the balance of excitatory/inhibitory synaptic input to hippocampal neurones through Neurogenin 3. J Neurochem 2006, 97:1269-1278.

15. Chacon PJ, Garcia-Mejias R, Rodriguez-Tebar A: Inhibition of RhoA GTPase and the subsequent activation of PTP1B protects cultured hippocampal neurons against amyloid beta toxicity. Mol Neurodegener 2011, 6:14.

16. Castrillo A, de Las HB, Hortelano S, Rodriguez B, Villar A, Bosca L: Inhibition of the nuclear factor kappa B (NF-kappa B) pathway by tetracyclic kaurene diterpenes in macrophages. Specific effects on NF-kappa Binducing kinase activity and on the coordinate activation of ERK and p38 MAPK. J Biol Chem 2001, 276:15854-15860.

17. Chacon PJ, Arevalo MA, Tebar AR: NGF-activated protein tyrosine phosphatase $1 \mathrm{~B}$ mediates the phosphorylation and degradation of I-kappa-Balpha coupled to NF-kappa-B activation, thereby controlling dendrite morphology. Mol Cell Neurosci 2010, 43:384-393.

18. Coiras M, Lopez-Huertas MR, Mateos E, Alcami J: Caspase-3-mediated cleavage of p65/RelA results in a carboxy-terminal fragment that inhibits IkappaBalpha and enhances HIV-1 replication in human T lymphocytes. Retrovirology 2008, 5:109.

19. Bae S, Bessho Y, Hojo M, Kageyama R: The bHLH gene Hes6, an inhibitor of Hes1, promotes neuronal differentiation. Development 2000, 127:2933-2943.

20. Cossins J, Vernon AE, Zhang Y, Philpott A, Jones PH: Hes6 regulates myogenic differentiation. Development 2002, 129:2195-2207.

21. Goslin K, Banker G: Experimental observations on the development of polarity by hippocampal neurons in culture. J Cell Biol 1989, 108:1507-1516.

22. Konig HG, Kogel D, Rami A, Prehn JH: TGF-\{beta\}1 activates two distinct type I receptors in neurons: implications for neuronal NF-\{kappa\}B signaling. J Cell Biol 2005, 168:1077-1086.

23. Yi JJ, Barnes AP, Hand R, Polleux F, Ehlers MD: TGF-beta signaling specifies axons during brain development. Cell 2010, 142:144-157.

24. Hocking JC, Hehr CL, Chang RY, Johnston J, McFarlane S: TGFbeta ligands promote the initiation of retinal ganglion cell dendrites in vitro and in vivo. Mol Cell Neurosci 2008, 37:247-260.

25. Koyano-Nakagawa N, Kim J, Anderson D, Kintner C: Hes6 acts in a positive feedback loop with the neurogenins to promote neuronal differentiation. Development 2000, 127:4203-4216.

26. Kaltschmidt B, Kaltschmidt C: NF-kappaB in the nervous system. Cold Spring Harb Perspect Biol 2009, 1:a001271.

27. Gavalda N, Gutierrez H, Davies AM: Developmental switch in NF-kappaB signalling required for neurite growth. Development 2009, 136:3405-3412.

28. Boersma MC, Dresselhaus EC, De Biase LM, Mihalas AB, Bergles DE, Meffert MK: A requirement for nuclear factor-kappaB in developmental and plasticity-associated synaptogenesis. J Neurosci 2011, 31:5414-5425.

29. Li J, Gu X, Ma Y, Calicchio ML, Kong D, Teng YD, Yu L, Crain AM, Vartanian TK, Pasqualini R, Arap W, Libermann TA, Snyder EY, Sidman RL: Nna1 mediates Purkinje cell dendritic development via lysyl oxidase propeptide and NF-kappaB signaling. Neuron 2010, 68:45-60.

30. Bhakar AL, Tannis LL, Zeindler C, Russo MP, Jobin C, Park DS, MacPherson S, Barker PA: Constitutive nuclear factor-kappa B activity is required for central neuron survival. J Neurosci 2002, 22:8466-8475.

31. Blondeau N, Widmann C, Lazdunski M, Heurteaux C: Activation of the nuclear factor-kappaB is a key event in brain tolerance. J Neurosci 2001, 21:4668-4677.

32. Barger SW, Horster D, Furukawa K, Goodman Y, Krieglstein J, Mattson MP: Tumor necrosis factors alpha and beta protect neurons against amyloid beta-peptide toxicity: evidence for involvement of a kappa B-binding factor and attenuation of peroxide and $\mathrm{Ca} 2+$ accumulation. Proc Natl Acad Sci USA 1995, 92:9328-9332.

33. Chao CC, Ma YL, Lee EH: Brain-derived neurotrophic factor enhances Bcl$\mathrm{xL}$ expression through protein kinase casein kinase 2-activated and nuclear factor kappa B-mediated pathway in rat hippocampus. Brain Pathol 2011, 21:150-162.

34. Mincheva S, Garcera A, Gou-Fabregas M, Encinas M, Dolcet X, Soler RM: The canonical nuclear factor-kappaB pathway regulates cell survival in a developmental model of spinal cord motoneurons. J Neurosci 2011, 31:6493-6503
35. O'Mahony A, Raber J, Montano M, Foehr E, Han V, Lu SM, Kwon H, LeFevour A, Chakraborty-Sett S, Greene WC: NF-kappaB/Rel regulates inhibitory and excitatory neuronal function and synaptic plasticity. $\mathrm{Mol}$ Cell Biol 2006, 26:7283-7298.

36. Arancio O, Zhang HP, Chen X, Lin C, Trinchese F, Puzzo D, Liu S, Hegde A, Yan SF, Stern A, Luddy JS, Lue LF, Walker DG, Roher A, Buttini M, Mucke L, Li W, Schmidt AM, Kindy M, Hyslop PA, Stern DM, Du Yan SS: RAGE potentiates Abeta-induced perturbation of neuronal function in transgenic mice. EMBO J 2004, 23:4096-4105.

37. Perkins ND: Integrating cell-signalling pathways with NF-kappaB and IKK function. Nat Rev Mol Cell Biol 2007, 8:49-62.

38. Caraci F, Battaglia G, Bruno V, Bosco P, Carbonaro V, Giuffrida ML, Drago F, Sortino MA, Nicoletti F, Copani A: TGF-beta1 Pathway as a new target for neuroprotection in alzheimer's disease. CNS Neurosci Ther 2011, 17:237-249.

39. Brionne TC, Tesseur I, Masliah E, Wyss-Coray T: Loss of TGF-beta 1 leads to increased neuronal cell death and microgliosis in mouse brain. Neuron 2003, 40:1133-1145.

40. Makwana M, Jones LL, Cuthill D, Heuer H, Bohatschek M, Hristova M, Friedrichsen S, Ormsby I, Bueringer D, Koppius A, Bauer K, Doetschman T, Raivich G: Endogenous transforming growth factor beta 1 suppresses inflammation and promotes survival in adult CNS. J Neurosci 2007, 27:11201-11213.

41. Tesseur I, Zou K, Esposito L, Bard F, Berber E, Can JV, Lin AH, Crews L, Tremblay P, Mathews P, Mucke L, Masliah E, Wyss-Coray T: Deficiency in neuronal TGF-beta signaling promotes neurodegeneration and Alzheimer's pathology. J Clin Invest 2006, 116:3060-3069.

42. Benes FM, Lim B, Matzilevich D, Walsh JP, Subburaju S, Minns M: Regulation of the GABA cell phenotype in hippocampus of schizophrenics and bipolars. Proc Natl Acad Sci USA 2007, 104:10164-10169.

43. Guo X, Wang XF: Signaling cross-talk between TGF-beta/BMP and other pathways. Cell Res 2009, 19:71-88.

44. Kennard S, Liu H, Lilly B: Transforming growth factor-beta (TGF- 1) downregulates Notch3 in fibroblasts to promote smooth muscle gene expression. J Biol Chem 2008, 283:1324-1333.

45. Singh B, Henneberger C, Betances D, Arevalo MA, Rodríguez-Tébar A, Meier JC, Grantyn R: Altered balance of glutamatergic/GABAergic synaptic input and associated changes in dendrite morphology after BDNF expression in BDNF-deficient hippocampal neurons. J Neurosci 2006, 26:7189-7200.

46. Luscher B, Fuchs T, Kilpatrick CL: GABAA receptor trafficking-mediated plasticity of inhibitory synapses. Neuron 2011, 70:385-409.

47. Sun M, Gewirtz JC, Bofenkamp L, Wickham RJ, Ge H, O'Connor MB: Canonical TGF-beta signaling is required for the balance of excitatory/ inhibitory transmission within the hippocampus and prepulse inhibition of acoustic startle. J Neurosci 2010, 30:6025-6035.

doi:10.1186/alzrt134

Cite this article as: Chacón and Rodríguez-Tébar: Increased expression of the homologue of enhancer-of-split 1 protects neurons from beta amyloid neurotoxicity and hints at an alternative role for transforming growth factor beta1 as a neuroprotector. Alzheimer's Research \& Therapy 2012 4:31.

\section{Submit your next manuscript to BioMed Central and take full advantage of:}

- Convenient online submission

- Thorough peer review

- No space constraints or color figure charges

- Immediate publication on acceptance

- Inclusion in PubMed, CAS, Scopus and Google Scholar

- Research which is freely available for redistribution

Submit your manuscript at www.biomedcentral.com/submit
C Biomed Central 